\title{
Pickup Modifications for Rural Transport Services in Cambodia
}

\author{
Matthew Ericson \\ Monash University
}

\begin{abstract}
This paper regards the operation of rural public transport services provided by pickup trucks and minibuses in Cambodia. Presented are survey data revealing how pickup modifications, especially cargo area canopies, are used to increase passenger and cargo capacity. A particular emphasis is placed on the importance of pickup transport services to economic activity. The results reveal that passengers traveling for economic reasons constitute 66 percent of passengers and carry 77 percent of the cargo weight. Transport operators may be modifying vehicles in response to their passengers' commercial requirements. This paper highlights both the economic benefits and safety risks of such modifications.
\end{abstract}

\section{Introduction}

There is a lack of rural transport services in much of the developing world and, where roads are poor, pickups are a preferred mode of transport, which is vital to economic development. Consequently, pickups are often fitted with benches and roof racks, enabling them to comfortably carry a dozen or more passengers on trips of up to $200 \mathrm{~km}$ (Starkey et al. 2002).

Cambodia's pickups carry 13 percent more passengers and 5 times the cargo weight of minivans (Rozemuller, Thou and Yan 2002). However, pickups are more susceptible to rollover because of their high center of gravity. The risk of rollover is heightened when goods are loaded on roofracks, as the center of gravity is raised 
even higher. Each additional passenger in the cargo area also raises the pickup's center of gravity, while their unrestrained weight movement further increases vehicle instability (Anderson et al. 2000). Banning overloaded vehicles, however, is unlikely to be successful in developing countries. Supply limitations mean commuters have few other options, and curtailing their travel would have severe social and economic consequences; transport services have been shown to be vital to economic development and poverty reduction in rural areas (Starkey et al. 2002; Nelson and Strueber 1991).

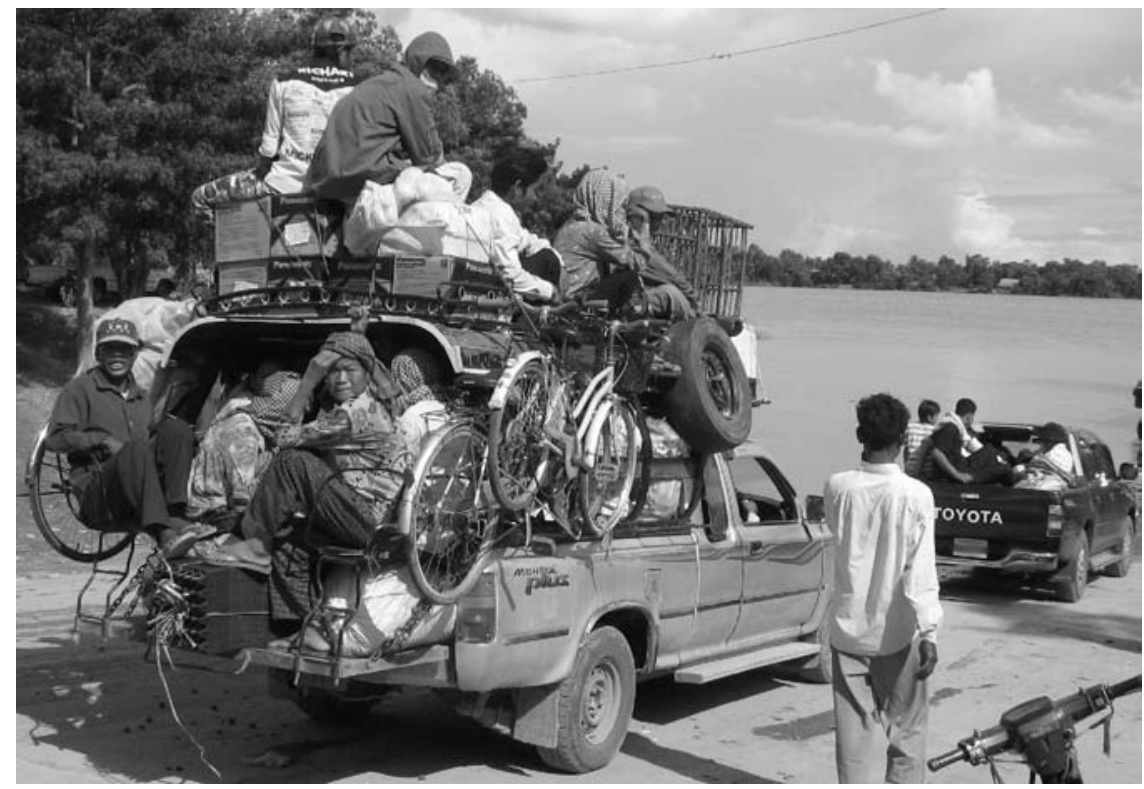

Figure 1. Pickup Taxi Fitted with Canopy Boarding the Preaek Ta Meak Ferry

As the main risk of injury in pickup trucks is from falls and ejections (CIPP 2000), a canopy attached to the pickup offers some protection for passengers. Canopies have proven effective in Australia's aboriginal communities (Macaulay et al. 2003; Hawkes 2005). The conditions in these communities are likened to those in thirdworld countries (Young 1995). These conditions include poor roads, an undersupply of vehicles, a predominance of old and poorly-maintained vehicles, and poor driver training (NTRS 2006).

Cambodia is a low-income country with a gross national income of US\$1820 per capita at purchasing power parity, and 80 percent of its 14.7 million people live in 
rural areas (World Bank 2009). Rural roads are in a poor state, and there are few motorized vehicles ( 0.8 four-wheelers per 100 people). Cambodia's fleet of transport providers is "fragmented," and most vehicles are aged and overloaded (World Bank 2007).

Pickup trucks operate as taxis throughout rural Cambodia. The pickup taxis follow regular bus-like routes but pick up and put down passengers where requested. The principal alternatives to pickup and minibus taxis are large air-conditioned coaches. Coaches are essentially luxury transport with a fixed price (e.g., US\$2.50 between Phnom Penh and Kampong Cham). In comparison, a pickup or minibus taxi costs around $\$ 1.25$. However, prices for taxis are negotiable, and greater discounts are available to passengers willing to ride on the roof or bonnet.

Accidents and injuries involving - though not necessarily resulting from-overloaded taxis are frequently reported in Cambodia's popular media. There is, for instance, the case of a passenger who was killed when her pickup lost control and overturned (Koh Santepheap 2006b). Similar cases of fatal accidents involving vulnerable minibus passengers are reported, including roof-riding passengers (Koh Santepheap 2006a). There are also events involving multiple casualties, including one involving more than 30 casualties (HIB 2007) and another involving 23 (AFP 2008).

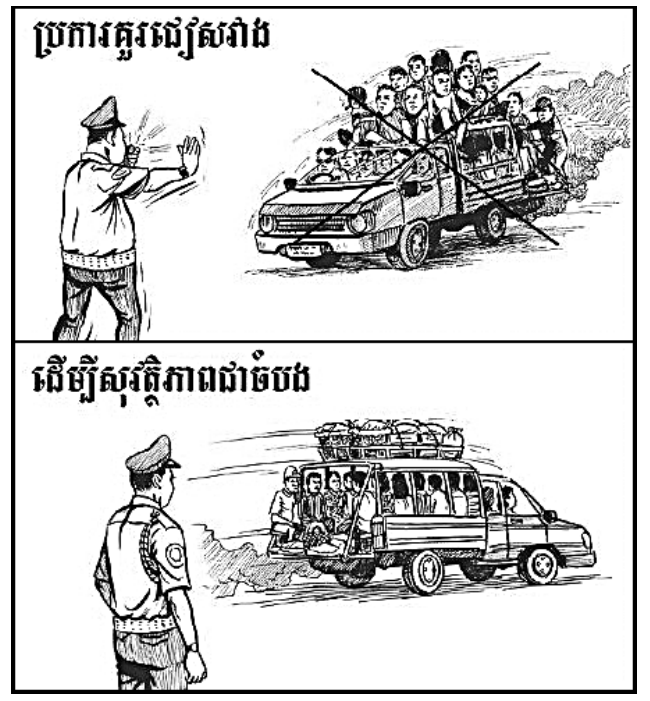

Figure 2. Sign Denoting Wrong Way/Correct Way (Neak Chea, 2006, used with permission) 


\section{Modifications to Pickups}

A taxi operator typically invests US\$5,000-\$7,000 in a pickup and modifications. There are six common modifications made to increase a pickup's carrying capacity:

- Bars for longitudinal chassis reinforcement are welded to the vehicle's underside.

- Additional leaf-springs are installed to reinforce the rear suspension.

- Firestone CV9000 heavy duty tires are fitted.

- A rope or chain is used to increase the tailgate's load capacity.

- Removable tailgate seats are fitted.

- A locally-manufactured canopy is used to increase load capacity and protect passengers.

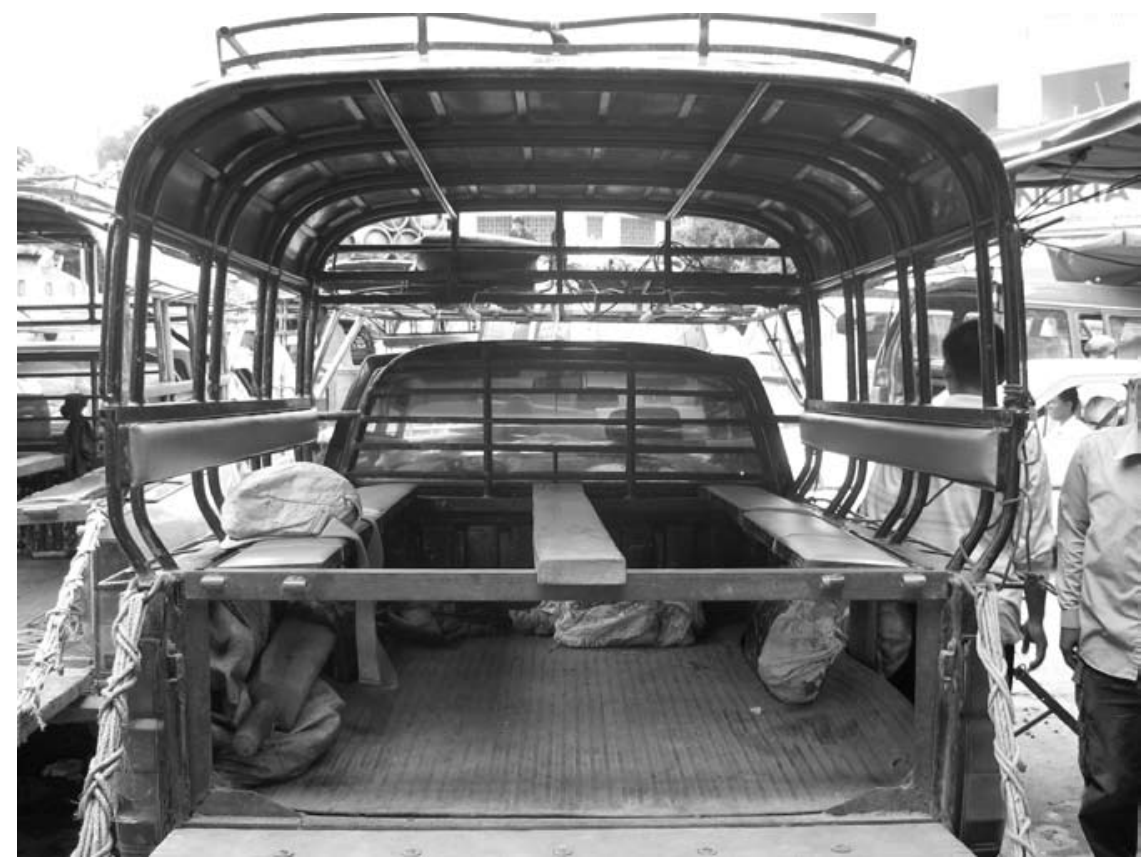

Figure 3. Common Canopy Design

Canopies are fitted to the pickup's cargo area. The canopy increases load capacity while offering passengers some protection from the elements as well as increased safety. The canopy costs around US\$450 fitted. 


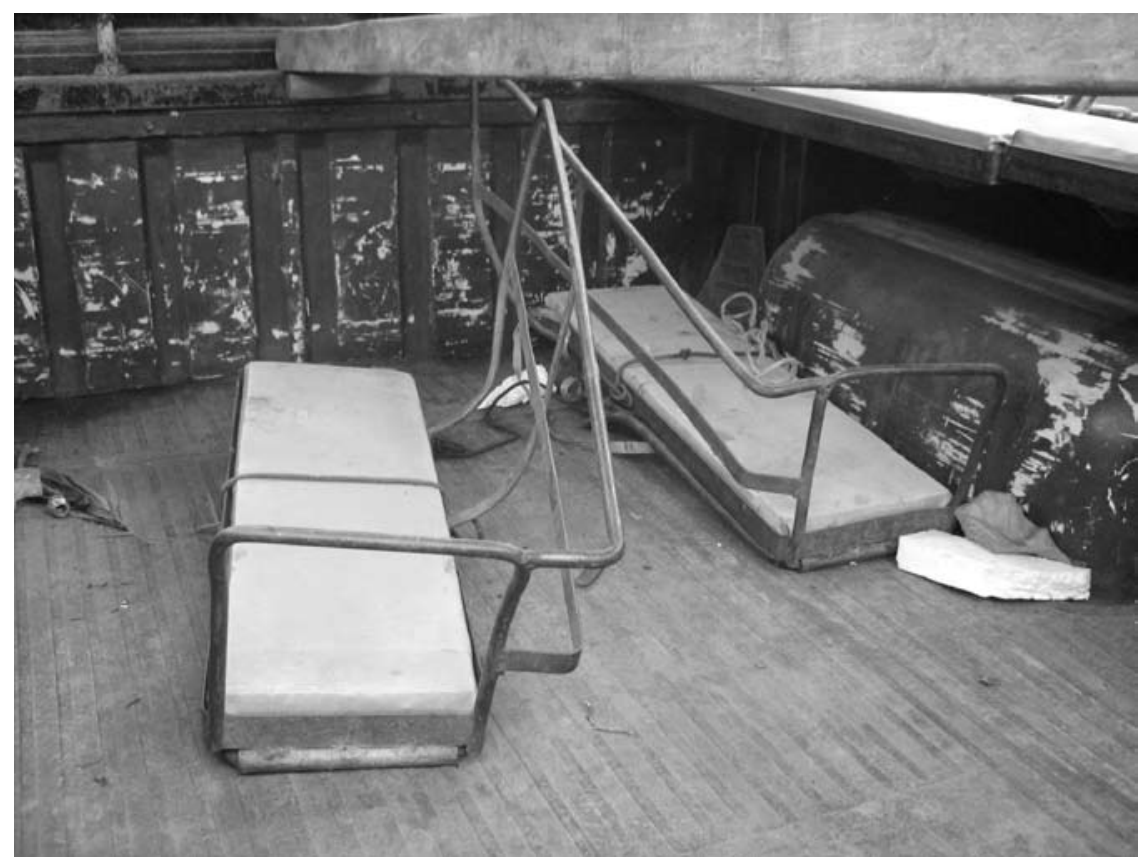

Figure 4. Removable Seats Attach to the Tailgate

These seats accommodate four additional passengers but are nominally prohibited. There is no discernible media support for the ban (see Figure 2), and passengers pay the same price for a fixed or removable seat. There are no known incidents of passengers falling from removable seats.

\section{Research Method}

These data emerged incidentally from a safety review of canopy use in Cambodia. A survey was undertaken of 100 adult passengers at three Kandal province ferry crossings (see Figure 5) located $25 \mathrm{~km}$ north northeast of Phnom Penh at Preaek Ta Meak $(\mathrm{N}=42)$, Svay Ath $(\mathrm{N}=17)$ and Ruessei Chrouy $(\mathrm{N}=41)$. Passengers were traveling routes along National Highway 6A between Phnom Penh and the eastern provinces of Kampong Cham, Prey Veng, and Svay Rieng. The sample distribution at each site was a proportional random selection of daily traffic estimated by ferry staff. The sample group for the structured-interview questionnaires was selected on the basis of convenience, as taxis were required to stop at the Kandal ferry terminals. The respondent selection was randomized by selecting the adult passenger seated in the middle of the row closest to the interviewer's approach. The passen- 
ger survey included 100 adult taxi passengers of both pickups and minibuses, as the services may be substitutable.

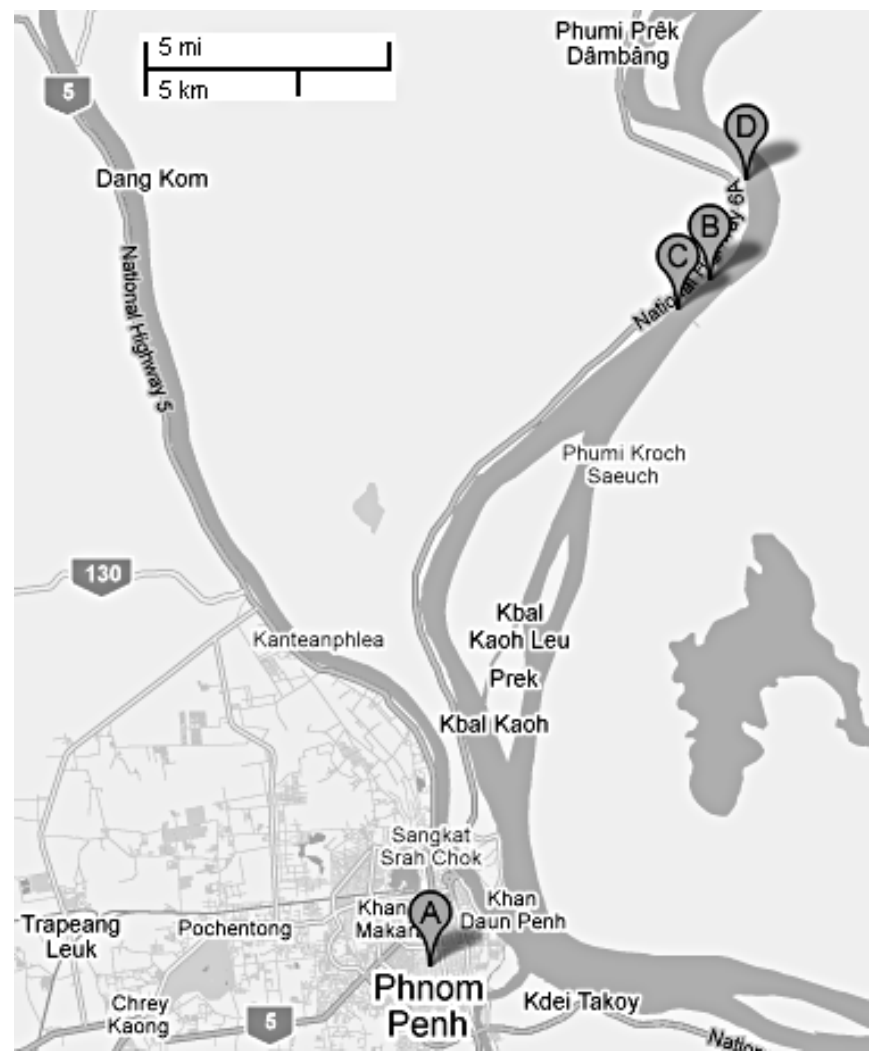

Figure 5. Phnom Penh (A) and Ferry Locations (B, C \& D) ${ }^{1}$

\section{Survey Results}

An overview of findings is presented in Table 1. There was an inverse Pearson correlation between cargo loads and passenger numbers $(-0.214, \mathrm{sig}=<0.05)$. There was a positive correlation between passengers' reason for travel and their accompanied cargo weight $(0.203, \mathrm{sig}=<0.05)$. There was an inverse correlation between gender $(1=$ female) and accompanied children $(-0.237$, sig $=<0.05)$. The most significant correlation was between reason for travel and the frequency of journeys per month $(0.447$, sig $=<0.01)$. 
The passengers and cargo distributions are illustrated in Figure 6 and 7, respectively. While 93 percent of passengers carry less than $100 \mathrm{~kg}$ in accompanied luggage, one passenger was carrying $2,000 \mathrm{~kg}$ in luggage. The average taxi was carrying $1,878 \mathrm{~kg}$ in the cargo area including passengers $(1,252 \mathrm{~kg})$ and luggage $(635 \mathrm{~kg})$. These calculations were made assuming that each adult passenger weighed an average of $65 \mathrm{~kg}$ and each child weighed $25 \mathrm{~kg}$; passenger and cargo weights were calculated using the average numbers of passengers and accompanied children (16.7 and 0.16, respectively) and $38 \mathrm{~kg}$ of accompanied luggage per adult passenger.

Table 1. Descriptive Statistics $(\mathbf{N}=100)$

\begin{tabular}{|l|c|c|c|c|c|}
\hline & Min & Max & Mean & Std. Deviation & Std. Error \\
\hline Vehicle & $0=$ Minibus & 1=Pickup & 0.91 & 0.29 & 0.03 \\
\hline Passengers & 3 & 40 & 16.65 & 7.20 & 0.72 \\
\hline Luggage (kg) & 0 & 2000 & 38.03 & 206.64 & 20.66 \\
\hline Age & 18 & 67 & 35.65 & 12.62 & 1.26 \\
\hline Gender & $0=$ Male & 1=Female & 0.53 & 0.50 & 0.05 \\
\hline Reason for travel & 0 & 3 & 1.70 & 1.00 & 0.10 \\
\hline Journeys/month & 1 & 60 & 8.09 & 12.70 & 1.27 \\
\hline \# accompanied children & 0 & 2 & 0.16 & 0.47 & 0.05 \\
\hline
\end{tabular}

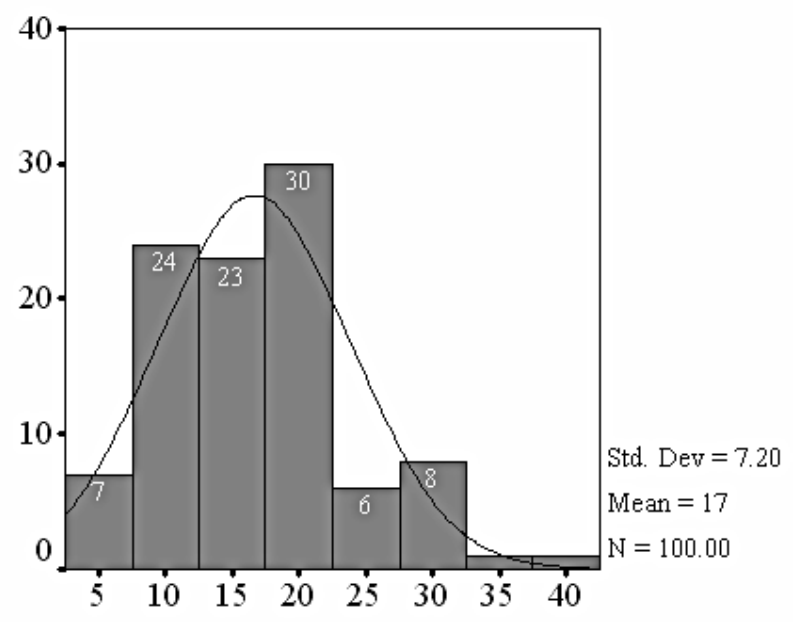

Passengers per vehicle

Figure 6. Distribution of Passengers per Vehicle 


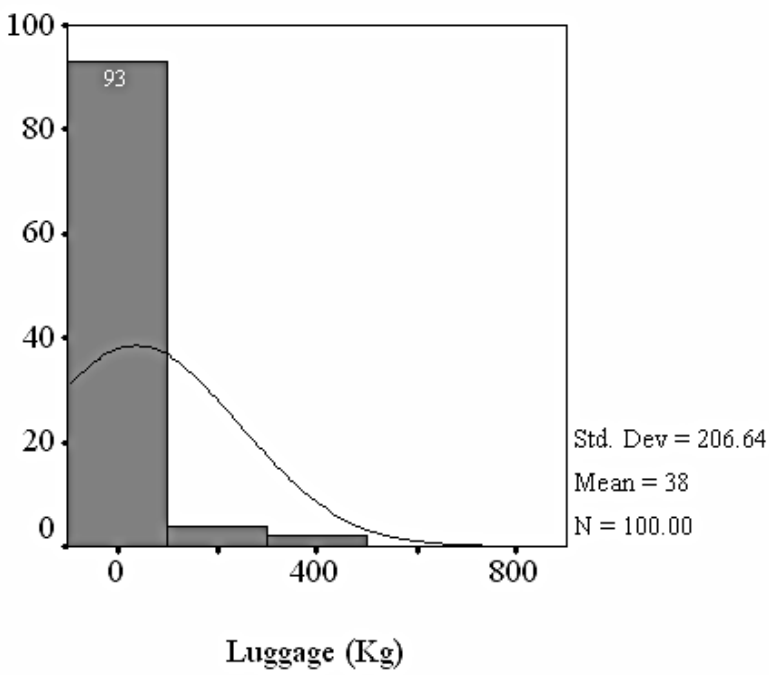

Figure 7. Distribution of Cargo per Vehicle

Each passenger's reason for travel was classified into one of four categories: economic, such as "to sell things at market"; health, such as "coming back from the hospital"; social, such as traveling "to the pagoda to perform a ritual"; and not classified, where the response was, in every case,"returning home" (seeTable 2). The 30 economic travelers were actively engaged in commercial activities such as capital acquisitions ("to buy fishery equipment") and wholesale trade ("to buy thing for selling at the market" or "taking things to sell at market"). Some travel reasons were marginally economic but have been assigned to one of the other categories. For instance, passengers traveling "to buy medicines for personal use" have been classified as health. Table 2 includes the frequency of travel by tertiles of journeys per month. The most frequent third of travelers took more than five journeys per month, while the least frequent travelers averaged fewer than three.

While 42 percent of passengers were traveling for social reasons, they represent only 20 percent of the market, as they make fewer journeys (Table 3). The higher journey frequency of economic travelers means they represent 66 percent of the market. Comparing reason for travel with respondent luggage weight, economic travelers' luggage is 2.5 times the average weight. This is important: economic travelers represent 66 percent of journeys and carry 77 percent of the luggage weight. They are the most important part of the market, and 97 percent of these passengers prefer to travel by pickup rather than minibus. 


\section{Table 2. Passenger Numbers and Luggage Weight by Frequency of Journeys per Month and Reason for Travel}

\begin{tabular}{|l|l|c|c|c|}
\cline { 4 - 5 } \multicolumn{2}{c|}{} & \multirow{2}{*}{$\mathbf{N}$} & \multicolumn{2}{|c|}{ Mean } \\
\cline { 4 - 6 } & & & Passengers & Luggage (Kg) \\
\hline \multirow{4}{*}{ Reason for travel } & Social & 42 & 17.21 & 8.67 \\
\cline { 2 - 5 } & Not classified & 19 & 16.58 & 26.21 \\
\cline { 2 - 5 } & Economic & 30 & 16.10 & 98.00 \\
\cline { 2 - 6 } & Health & 9 & 16.00 & 0.11 \\
\hline \multirow{3}{*}{ Tertiles of journeys/month } & Most (>5) & 36 & 16.61 & 85.69 \\
\cline { 2 - 6 } & Mid (4-5) & 19 & 17.32 & 16.32 \\
\cline { 2 - 5 } & Least (<3) & 45 & 16.40 & 9.07 \\
\hline
\end{tabular}

Table 3. Luggage Weights and Monthly Travel Frequency by Reason for Travel

\begin{tabular}{|l|c|c|c|c|c|c|c|}
\hline \multirow{2}{*}{$\begin{array}{l}\text { Reason for } \\
\text { Travel }\end{array}$} & \multirow{2}{*}{$\mathbf{N}$} & \multicolumn{3}{|c|}{ Travel Frequency (per month) } & \multicolumn{3}{c|}{ Luggage weight (kg) } \\
\cline { 3 - 8 } & & Mean & Sum & \% of Sum & Mean & Sum & \% of Sum \\
\hline Social & 42 & 4 & 167 & 20.6 & 8.7 & 364 & 9.6 \\
\hline Economic & 30 & 17.9 & 537 & 66.4 & 98.0 & 2940 & 77.3 \\
\hline Health & 9 & 2.8 & 25 & 3.1 & 0.1 & 1 & 0.0 \\
\hline Not classified & 19 & 4.2 & 80 & 9.9 & 26.2 & 498 & 13.1 \\
\hline Total & $\mathbf{1 0 0}$ & $\mathbf{8}$ & $\mathbf{8 0 9}$ & $\mathbf{1 0 0}$ & $\mathbf{3 8}$ & $\mathbf{3 , 8 0 3}$ & $\mathbf{1 0 0 . 0}$ \\
\hline
\end{tabular}

\section{Conclusion}

This research provides further evidence of the important role pickup trucks play in facilitating transport and economic activity in rural areas. Most notably, passengers traveling for economic reasons constitute 66 percent of the market and accompany 77 percent of the cargo load. More importantly, this paper documents the technical modifications made to pickups so they can carry additional passengers and cargo. Rural public transport in Cambodia is benefiting from a capacity improvement by using cargo canopies and removable tailgate seats on pickup trucks. These modifications enable taxis to transport an average of 17 passengers plus a $635 \mathrm{~kg}$ cargo load.

Given the important results, further research is required. A study with a larger sample should be undertaken and should be designed with the express objective 
of identifying trends in cargo and passenger transport with and without cargo canopies and by various vehicle types. A longitudinal study that examines changes over time and includes vehicle weights would yield data better able to inform transport policy makers. Comparative research in other jurisdictions also needs to be undertaken.

This paper also raises important safety implications for policy makers. By increasing the load capacity of the pickup at a higher center of gravity, the canopy and vehicle modifications reduce the stability and handling of the vehicle. To what extent this detracts from the canopy's protection of cargo-space occupants is very important, but unknown. Consequently, a high priority for further research is the real-world crash effectiveness of the canopy; more needs to be known about passenger injuries and the circumstances in which the most serious occur. Even with a canopy, injuries resulting from shifting cargo (Williams and Goins 1981), impact with the interior of the cargo area (Anderson et al. 2000), or the canopy becoming detached (Children's Safety Network 2005) could be expected. Ultimately, as Agran et al. (1994) warned, "there is no safe, crash-tested means of travel in the cargo areas of pickup trucks."

\section{Acknowledgements}

Thanks to two anonymous reviewers for their suggested improvements; lan Johnston, David Logan, and Bruce Corben of the Monash University Accident Research Centre; David Chandler of the Monash Asia Institute; the Monash Research Graduate School; the staff and crew of the Kandal ferries; Uy Sareth and Kim Pagna of the Coalition for Road Safety; and the staff of the Commissariat General of National Police, Department of Land Transport, Department of Rural Roads, and Handicap International Belgium. This paper was prepared with the assistance of a Postgraduate Publications Award from the Monash Research Graduate School.

\section{Endnotes}

${ }^{1}$ The ferries are situated at $+11^{\circ} 44^{\prime} 40.49 ",+104^{\circ} 59^{\prime} 29.04^{\prime \prime}$ (N 11.74458 E 104.99140), 23.1 km NxNE of Phnom Penh; +11 45' 10.91", +105 0' 3.13" (N 11.75303 E

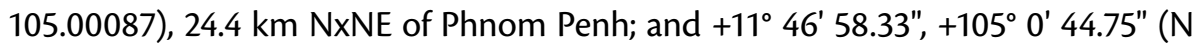
11.78287 E 105.01243), $27.9 \mathrm{~km}$ NxNE of Phnom Penh. A satellite map has been prepared at http://mapper.acme.com/?ll=11.69460,104.96784\&z=11\&t=H\&marker $0=11.55000 \% 2$ C $104.91669 \% 2$ CPhnom $\% 20$ Penh\&marker $1=11.75303 \% 2 C 105.00087$ 
\%2C24.4\%20km\%20NxNE\%20of\%20Phnom\%20Penh\&marker2=11.78287\%2C105. 01243\%2C27.9\%20km\%20NxNE\%20of\%20Phnom\%20Penh\&marker3=11.74458\%2 C104.99140\%2C23.1\%20km\%20NxNE\%20of\%20Phnom\%20Penh

\section{References}

AFP. 2008. Drivers beware at New Years. Phnom Penh Post, 4 April.

Agran, P., D. Winn, and C. Anderson. 1994. Injuries to occupants in cargo areas of pickup trucks. Western Journal of Medicine 161(5): 479-482.

Anderson, C. L., P. F. Agran, D. G. Winn, and S. Greenland. 2000. Fatalities to occupants of cargo areas of pickup trucks. Accident Analysis \& Prevention 32(4): 533-40.

Children's Safety Network. 2005. Youth Riding in Pickup Truck Cargo Areas. Newton: Children's Safety Network.

CIPP (Committee on Injury and Poison Prevention). 2000. Children in pickup trucks. Pediatrics 106(4): 857-859.

Hawkes, E. 2005. Open Load Space Project. Perth: Office of Road Safety, Department of Premier and Cabinet.

HIB (Handicap International Belgium). 2007. Cambodia Road Traffic Accident and Victim Information System: Monthly Report, March 2007. Phnom Penh: Handicap International Belgium.

Koh Santepheap. 2006a. Broken neck, death in fall from roof of 12-seat taxi: 8 injured. Koh Santepheap, 13 August, 9.

Koh Santepheap. 2006b. Taxi has flat tyre and overturns: 1 killed and 9 injured. Koh Santepheap, 23 June, 1, 7.

Macaulay, J., R. Thomas, N. Mabbot, T. Styles, C. Edmonston, M. Sheehan, and C. Schonfeld. 2003. Australian Indigenous Road Safety. Melbourne: ARRB.

Nelson, D. C., and J. V. Strueber. 1991. The effect of open-back vehicles on casualty rates: the case of Papua New Guinea. Accident Analysis \& Prevention 23(2-3): 109-17.

NTRS (Northern Territory Road Safety Taskforce). 2006. Safer Road Use: A Territory Imperative. Darwin: Northern Territory Government. 
Rozemuller, B., P. Thou, and S. Yan. 2002. Rural Transporters: A Survey of Transport Businesses in Rural Cambodia. Technical Assistance to the Labour-Based Rural Infrastructure Works Programme reports, No. CMB/97M02/SID. Phnom Penh: Ministry of Rural Development/International Labour Organisation.

Starkey, P., S. Ellis, J. Hine, and A. Ternell. 2002. Improving rural mobility: options for developing motorized and nonmotorized transport in rural areas. World Bank Technical Papers, No. 525. Washington: World Bank.

Williams, A. F., and S. E. Goins. 1981. Fatal falls and jumps from motor vehicles. American Journal of Public Health 71(3): 275-279.

World Bank. 2007. Overview. World Bank 2007 [cited 24 October 2007]. Available from http://go.worldbank.org/BTXYYERF51.

World Bank. 2009. World Development Indicators 2008. Washington: World Bank.

Neak Chea. 2006. The wrong way/Correct. Neak Chea 8, 30.

Young, E. A. 1995. Third World in the First: Development and Indigenous Peoples. London: Routledge.

\section{About the Author}

MATTHEW ERICSON (meri5441@gmail.com) recently submitted his PhD at the Monash University Accident Research Centre (MUARC). He holds Bachelor of Economics (Honours) and Master of Public Policy (Honours) degrees from the University of Sydney. His primary research interest is in road transport safety. 